\title{
INVENTARISASI PUISI MANTRA \\ DI KECAMATAN SITURAJA KABUPATÉN SUMEDANG (ULIKAN STRUKTURAL)
}

\author{
Dina Siti Ningrum \\ dinasitin@gmail.com \\ MGMP Kabupaten Sumedang
}

\begin{abstract}
ABSTRAK
Penelitian ini dilatarbelakangi oleh berkurangnya keberadaan puisi mantra di masyarakat serta berkurangnya orang yang mempunyai mantra. Tujuan dari penelitian ini yaitu mendeskripsikan; 1) puisi mantra di Kecamatan Situraja, Kabupaten Sumedang; 2) klasifikasi puisi mantra di Kecamatan Situraja, Kabupaten Sumedang; dan 3) analisis struktur mantra yang ditemukan di Kecamatan Situraja, Kabupaten Sumedang. Penelitian ini menggunakan metode deskriptif, dengan tekhnik studi pustaka, wawancara, dan dokumentasi. Berdasarkan hasil dari penelitian ini, data puisi mantra yang terkumpul adalah sejumlah 105 puisi mantra dari 12 narasumber, yang terdiri dari 22 asihan, 22 jangjawokan, 38 ajian, 6 singlar, 3 rajah, 14 jampé. Selanjutnya, dari 105 puisi mantra dipilih jadi 25 puisi mantra yang mencakup 9 asihan, 4 jangjawokan, 4 ajian, 2 singlar, 1 rajah, jeung 5 jampé. Hasil dari analisis 25 puisi mantra yaitu: wangun dan wirahmanya tidak teratu, kebanyakan dari puisi mantra dibangun lebih dari 8 baris, purwakanti yang sering muncul adalah purwakanti mindoan kawit, purwakanti mindoan kawit, larasmadya, maduswara, laraspurwa, jeung laraswekas. Bangbalikan yang sering muncul adalah bangbalikan rantay rakitan a b/ a c dan bangbalikan runtuy puhu, dan pencitraan yang sering ditemukan adalah pencitraan penglihatan (visual) dan pencitraan perasaaan (taktil). Dapat disimpulkan, puisi mantra yang terkumpul dari masyarakat Kecamatan Situraja, Kabupaten Sumedang mempunyai manfaat untuk memperluas dan menambah pengetahuan mengenai sastra dan budaya Sunda, serta bisa memahami pembahasan struktur puisi mantra.
\end{abstract}

Kata Kunci: puisi mantra, struktural

\section{INVENTORY SPELLING POETRY IN KECAMATAN SITURAJA KABUPATEN SUMEDANG (Structural Analysis)}

\begin{abstract}
Background this study based on the reduced presence of poetry in society as well as a reduced spell people know and have been rarely spell. The purpose of the study is to describe; 1) poem mantra in district Situraja, Sumedang; 2) classification of poem mantra in district Situraja, Sumedang; and 3) structure analysis found in district Situraja, Sumedang. This research uses descriptive method, with the dwarf in the study of the literature, interviews and documentation. Based on the results of this research, the data collected is the mantra of poems a number of 105 poem spell of 12 speaker, consisting of 22 asihan, 22 jangjawokan, 38 ajian, 6 singlar, 3 rajah., 14 jampé. Next, from 105 poem mantra was chosen so the mantra of poetry includes 25 poem, 9 asihan 4 jangjawokan, 4 singlar, 2 ajian, 1 rajah jeung 5 jampé. The results of the analysis of 25 poems mantra: wangun jeung wirahma, most of the poem spell built more than 8 lines, purwakanti faqs purwakanti mindoan is purwakanti mindoan, kawit kawit, larasmadya, maduswara, laraspurwa
\end{abstract}


laraswekas, bangbalikan and who often appears is bangbalikan rantay assembled a b/a $c$ and bangbalikan runtuy puhu, and imaging often found is eyesight (visual) imaging and imaging sence (tactile). It can be inferred, the poem spell collected from the community Subdistrict Situraja, Sumedang has benefits to expand and add to the knowledge of the literature and culture of Sundanese, and could understand the discussion of the structure of the poem spell.

Keywoards: spell peotry, structural

\section{PENDAHULUAN}

Karya sastra lahir dari hasil proses keatif pengungkapan rasa manusia yang diciptakan melalui bahasa. Hal tersebut sejalan dengan pendapat Wellek dan Warren (2014, hlm. 3) yang menyatakan bahwa sastra merupakan suatu kegiatan kreatif dalam karya seni. Hal serupa dinyatakan pula oleh Isnendes (2010, hlm. 10) bahwa sastra sebagai proses kreatif tidak lain adalah ekspresi pengarang dalam menggelar karyanya.

Sebagai sastra lisan dalam bentuk puisi, mantra menjadi kebanggaan suatu kelompok masyarakat, mantra mempunyai nilai-nilai yang luhur karena merupakan ciri serta ekspresi dari suatu kebudayaan yang tersebar secara lisan. Hutomo (1991, hlm.3-4) menjelaskan bahwa sastra lisan mempunyai ciri-ciri yaitu; 1) tersebar melalui ucapan, 2) tersebar di masyarakat desa, masyarakat di luar kota, atau masyarakat yang belum mengenal huruf, 3) menggambarkan ciri budaya suatu masyarakat, sebab merupakan warisan budaya yang menggambarkan situasi zaman saat itu, tetapi sejalan dengan perubahan sosial, 4) tidak diketahui siapa pengarangnya jadi dimiliki oleh masyarakat, 5) mempunyai corak puitis dan sitematis, 6) ada beberapa versi, 7) bahasa yang digunakan adalah bahasa lisan, mencakup dialek, serta jarang diucapkan secara lengkap.

Mantra salah satu karya sastra berbentuk lisan dan tergolong pada folklore lisan. Sebagai karya sastra lisan yang mempunyai nilai-nilai yang luhur. Danandjaja (dalam Pudentia, 208, hlm.73) menjelaskan bahwa folklore melambangkan atau menggambarkan cara berpikir seorang manusia. Pada zaman dulu mantra tersebar di masyarakat dan mempunyai peran yang penting dalam kehidupan manusia. Adanya mantra selalu dikaitkan dengan kepercayaan seorang manusia.

Mulyana (dalam Cahyadi, 2014 hlm. 3) menyebutkan bahwa puisi merupakan bentuk sastra yang memiliki unsur pengulangan kata dan pengulangan bunyi sebagai bagian dari ciri khas puisi. Adapun menurut Hasanuddin (dalam Jaya, 2013, hlm. 88) puisi merupakan ungkapan rasa yang imajinatif dan abstrak, berdasarkan kejadian-kejadian yang dipikirkan oleh pengarang. Leigh Hunt (dalam Jaya 2013, hlm,88) menjelaskan bahwa puisi merupakan keterampilan menuangkan apa yang dirasakan dan dipikirkan dalam bentuk tulisan melalui bahasa yang indah dan imajinatif. Leigh Hunt (dalam Jaya 2013, hlm, 88) menjelaskan bahwa puisi merupakan keterampilan menuangkan apa yang dirasakan dan dipikirkan dalam bentuk tulisan melalui bahasa yang indah dan imajinatif.

Mantra erat kaitannya dengan istilah doa khusus yang diyakini memiliki kekuatan gaib. Meskipun tidak semua manusia memiliki mantra, umumnya mantra merupakan warisan dari nenek moyangnya dan memilki syarat-syarat yang pasti, dan ada beberapa pantangan yang tidak boleh dilanggar. Peran mantra untuk masyarakat zaman dulu, tidak bisa dipisahkan dari kehidupan sehari-hari. Istilah mantra biasa dikaitkan dengan kepercayaan seorang manusia. Mantra 
juga erat kaitanya dengan istilah doa khusus, juga dilihat dari bahasanya yang sangat arkais dan estetis serta di dalamnya mengandung kekuatan gaib. Hal tersebut sejalan dengan pendapat Rusyana (1970, hlm.3) yang menjelaskan bahwa mantra dikaitkan dengan hal-hal yang memiliki kekuatan magis. Adanya kekuatan magis yaitu dipakai manusia untuk mencapai suatu maksud atau tujuan dengan cara yang ada kaitannya dengan ilmu supranatural. Sejalan dengan pendapat Padmosukotjo (dalam Retnaningsih, 2012, hlm. 78) mantra bisa berupa formula dari kata-kata yang ditulis atau dimanfaatkan untuk mengasilkan efek yang pasti. Artinya mantra disebut warisan yang turun temurun yang sifatnya anonym serta ada kaitannya dengan kepercayaan religi dan dunia gaib. Bahasa yang digunakan dalam mantra umumnya bahasa yang tidak dimengerti, bahasa kuno atau bahasa arkais.

Puisi mantra sebagai salah satu jenis puisi yang berupa satu struktur, yang dibangun oleh beberapa unsur. Pada prinsipnya analisis struktural mempunyai tujuan untuk menggambarkan hubungan semua unsur dan semua aspek karya sastra secara tuntas. Berdasarkan pendapat Teeuw (dalam Kowara, 2013, hlm. 13) menyebutkan, struktural merupakan pendekatan yang menegaskan karya sastra sebagai struktur yang bersifat otonom. Oleh sebab itu perlu dilakukan analisis terhadap unsur-unsur pembangunnya. Rusyana menjelaskan bahwa puisi mantra mempunyai unsur purwakanti, puisi wirahma merdika, serta bangbalikan. Untuk itu, strukturnya mencakup: wangun jeung wirahma, purwakanti, bangbalikan, juga pencitraan puisi mantra yang terdapat di Kecamatan Situraja, Kabupaten Sumedang.

Di Kecamatan Situraja masih terdapat mantra, tetapi tidak semua orang mempunyai mantra, hal itu dikarenakan tidak sembarangan orang mendapat kepercayaan dalam menjaga mantra jalma. Hanya dipercayakan kepada orang-orang yang mempunyai garis keturunan dari leluhurnya, orang yang mempunyai mantra tentu sebelumnya harus memenuhi syarat-syarat tertentu serta larangan yang tidak boleh dilanggar. Hal tersebut merupakan latarbelakang mantra hanya terdapat di beberapa orang tertentu atau bisa disebut sebagai orang pintar yang bisa disebut dengan sebutan 'dukun'. Mantra yang digunakan bertujuan untuk keperluan tertentu, seperti ngajampé, menyebuhkan orang yang sakit, serta mencari petunjuk tentang keberadaan barang yang hilang. Sebagai contoh, ketika ada orang yang sedang sakit, dan anak kecil yang kemasukan oleh makhluk halus, cukup dengan membawa dan meminta untuk diobati 'jampé'.

Di Kecamatan Situraja masih ada mantra yang tersebar, tetapi tidak semua orang mempunyai mantra sebab tidak sembarang orang yang bisa dipercaya memlihara dan menjaganya. Sebagai warisan dari nenek moyang, manusia yang memiliki mantra tentu akan memenuhi syarat-syarat yang pasti dan pantangan yang tidak boleh dilanggar. Ini salah satu hal yang menyebabkan mantra hanya ada pada orang-orang yang dijadikan tempat bertanya (berdukun) dan penyembuhan.

$$
\text { Umumnya oleh orang-orang }
$$

tempat bertanya atau sering disebut dengan dukun, mantra digunakan untuk keperluan yang jelas, diantaranya untuk jampi-jampi, menyembuhkan orang yang sakit, dan menelusuri barang yang hilang. Salah satu contohnya, apabila ada orang yang terserang sakit dan anak kecil yang dirasuki makhluk halus, cukup membawa air ke orang pintar atau dukun, untuk diobati atau dijampi.

Sekarang dengan adanya kemajuan teknologi yang semakin pesat dan pola piker masyarakat yang sudag berbeda, menyebabkan masyarakat Kecamatan Situraja sudah jarang yang percaya pada kekuatan mantra, hal tersebut juga menyebabkan puisi mantra tergeser serta hampir punah. Penelitian ini sekaligus menginventarisasi puisi mantra, 
karena masih banyak mantra yang belum didokumentasikan. Juga bisa memperkaya ilmu untuk orang sunda terutama pemuda. Sunda bisa mengetahui puisi mantra yang tersedia di kecamatan Situraja. Selain itu, sebagai sakah satu usaha untuk meyakinkan bahwa orang sunda kaya oleh bahasa dan budayanya dan bisa dijadikan pembelajaran untuk kehidupan.

\section{METODE}

Penelitian ini termasuk penelitian kualitatif yang menggunakan pendekatan deskriptif. Metode deskriftif yaitu metode penelitian yang menelusuri akumulasi data dengan cara deskriptif, tidak menggunakan uji hipotesis, tidak membuat ramalan/prediksi, dan tidak bertujuan memberi implikasi yang seterusnya dianalisis menggunakan interpretasi (Suyatna (2002, hlm.14). juga sejalan dengan Sukardi (2013, hlm. 157) yang menjelaskan metode deskriptif yaitu metode yang bertujuan untuk menjawab pertanyaan penelitian atau hipotesis yanga ada hubungannya dengan keadaan serta kejadian saat ini. Tujuannya untuk menggambarkan dakta dan karakteristik objek dengan sistematis.

Data dalam penelitian ini terbagi menjadi dua data yaitu: 1) data primer, berupa data yang ditelusuri secara langsung ke lapangan; 2) data sekunder, dimana data dihasilkan dari sumbersumber tertulis, dokumentasi, jurnal, dan internet yang ada kaitannya dengan penelitian. Data yang diambil berupa puisi mantra di Kecamatan Situraja, Kabupaten Sumedang. Dari 15 desa, yang dijadikan tempat untuk pengambilan data dalam penelitian ini hanya empat desa atau 26,66\%. Narasumber dalam penelitian ini yaitu ada 12 narasumber yang terdiri dari 3 perempuan dan 9 laki-laki. Puisi mantra yang dikumpulkan dari 12 narasumber ada 105 mantra, adapun yang dijadikan data analisisnya yaitu $23,80 \%$ atau 25 mantra, berdasar kepada peneliti yang hanya mengambil conto dari setiap puisi mantra berdasarkan pada fungsi dan jenis mantra yang telah disesuai.

Instrument nu digunakan yatu instrumen yang dibuatoleh peneliti sendiri, yaitu instrument untuk mengumpulkan data dan instrumen untuk mengolah data. Menurut Sugiyono (2016, hlm. 222). Instrumen dalam penelitian kualitatif yaitu, alat yang digunakan oleh penelitinya sendiri. Oleh sebab itu, peneliti sebagai instrument harus divalidasi, artinya peneliti kualitatif harus siap melaksanakan penelitian seterusnya ke lapangan.

Penelitian ini menggunakan teknik telaah pustaka dengan cara membaca buku-buku yang ada kaitannya dengan kajian struktural dan buku yang berkaitan dengan puisi mantra. Selain itu, dilakukan juga wawancara kepada narasumber yang mempunyai kaitan dengan data yang akan diteliti, terutama puisi mantra yang dimiliki oleh narasumber. Selain dari itu dokumentasi dari hasil data yang menyeluruh, dengan cara mengabadikan dan merekam.

\section{HASIL DAN PEMBAHASAN}

Hasil dari penelitian puisi mantra yang telah dilaksanakan di Kecamatan Situraja, Kabupatén Sumedang terdapat beberapa pembahasan yaitu: deskripsi puisi mantra; pengelompokan puisi mantra; serta analisis struktur mantra seperti di bawah ini.

\section{Deskripsi Puisi Mantra di Kecamatan Situraja Kabupaten Sumedang}

Dari 15 desa, yang dijadikan tempat penelitian ini hanya 4 desa atau $26,66 \%$. Puisi mantra sekarang ini sudah mulai ditinggalkan oleh masyarakat di Kecamatan Situraja, Kabupaten Sumedang tina hasil data anu kapanggih di Kecamatan Situraja, Kabupatén Sumedang hanya tekumpul 105 mantra. Sedangkan yang dianalisis sebanyak 25 atau $23,80 \%$. Puisi mantra yang telah ditemukan di Kecamatan Situraja, Kabupaten Sumedang yaitu: jampé anu 
maot bisi bau, panyinglar guludug, paranti malidkeun, panganggo geusan ulun, ngembat nyi sri, kasemaran, paranti ngajiad menyan, asihan (I), jampé raheut, pélét, kasumedangan, asihan si ratu gambuh, asihan II, jampé raheut II, paranti pangembat, jampé meuncit hayam, kasemaran II, pangrajah, jampé mules beuteung, jampé tutung ku seuneu, jampé mandi, jampé dangdan, jampé keur nyageurkeun nu gering, jeung jampé dagang. Data tersebut diperoleh dari narasumber-narasumber yang telah diwawancara sebelumnya, kebanyakan dari narasumber yang memberikan mantranya adalah lalaki sejumlah 9 orang, sedangkan narasumber wanita berjumlah 3 orang. Pernana ke 12 narasumber di Kecamatan Situraja, Kabupaten Sumedang adalah sebagai tokoh 'sesepuh' di masarakat.

\section{Klasifikasi Puisi Mantra di Kecamatan Situraja Kabupaten Sumedang}

Dalam Rusyana (1970, hlm. 11)

klasifikasi puisi mantra dikelompokan berdasarkan pada fungsi dan tujuan penggunaan mantra, yaitu: asihan, jangjawokan, ajian, singlar, rajah, dan jampé. Sedangkan menurut Isnendes (2010, hlm. 57) menyebutkan bahwa kriteria dalam pengelompokan puisi mantra berdasarkan pada: 1) tujuan digunakan mantra, 2) makhluk halus yang disebutnya, dan 3) syarat-syarat untuk memiliki mantra.

Puisi mantra yang berhasil dikumpulkan di Kecamatan Situraja, Kabupatén Sumedang dalam penelitian ini berjumlah 105 mantra, yang meliputi: 22 asihan, 22 jangjawokan, 38 ajian, 6 singlar, 3 rajah, dan 14 jampé. Klasifikasi dalam penelitian ini berdasarkan pada konsep Rusyana serta kriteria klasifikasi mantra Isnendes yang mengelompokan mantra berdasarkan pada fungsi dan tujuan penggunaan mantra. Dari hasil klasifikasi mantra dalam penelitian ini analisis mantra sebanyak 25 atau $23,80 \%$ mantra, yang meliputi salapan asihan, opat jangjawokan, opat ajian, dua singlar, hiji rajah, dan lima jampé.

\section{Asihan}

Asihan bertujuan untuk mengusai jiwa orang lain ataupun seseorang yang dicintai supaya bisa berbalik mencintai, serta orang yang melafalkan asihan terpancar aura ketampanan atau kecantikannya sehingga semua orang terkesima. Jiwa yang dijadikan objeknya merupakan jiwa seseorang yang dicintai serta jiwa pribadi. Makhluk halus atau sesembagan yang disebut dalam asihan hamper semuanya termasuk kategori makhluk baik.

Contoh puisi mantra Asihan:
Asihan keur cecekelan awéwé
Biwir aing ku si panarik
huntu aing ku si pangirut
létah aing ku si pangalap
Asihan aing mungguh di tikoro dunya di seberang di Palembang
di gudang di Malayu,
nu hérang Kusumawarti,
sia asih... (sebutkan nama orang yang dimaksud) ka awaking.

Puisi mantra di atas termasuk kepada kelompok puisi mantra jenis asihan, karena terlihat dari beberapa kalimat yang mempunyai maksud untuk mengusai jiwa seseorang yang dicintai akan berbalik mencintai serta membuat orang lain pun terkesima. Terlihat pada kalimat sia asih ... (sebutkan nama yang dimaksudkan) ka awaking, dari kata tersebut berarti bahwa orang yang disebutkan oleh yang membacakan mantra berbalik menyukai dan mencintai.

\section{Jangjawokan}

Jangjawokan digunakan ketika hendak melakukan suatu pekerjaan yang diharapkan dapat menghasilkan hasil yang memuaskan, sehingga yang melaksanakan kegiatan pun ada dalam kondisi baik. Sering dilafalkan pada kegiatan sehari- 
hari. Makhluk sesembah yang disebutkna pun kebanyak makhluk halus yang baik. Contoh Puiai Mantra Jangjawokan:

\section{Jampé Dangdan}

Bismillahirohmanirrohim

Samping aing samping wayang

samping wayang sakoléngkang

sabeulit matak jadi sakit

ditilik ti gigir lengik

disawang ti tukang lenjang

ti teuteup ti hareup sieup

sieup tetep sieup eunteup

Puisi mantra di termasuk kepada kelompok puisi mantra jangjawokan, terlihat dari kalimat ti samping aing samping wayang, samping wayang sakoléngkang, sabeulit matak jadi sakit. Dari kalimat tersebut dapat terlihat tujuannya yaitu untuk melalukan suatu pekerjaan yang mendapatkan hasil yang memuaskan. Kata samping berarti sedang melakukan perkerjaan, yaitu bercermin dan mengenakan samping.

\section{Ajian}

Ajian sering kali digunakan untuk mendapatkan kekuatan pribadi, supaya berwibawa, pemberani, tidak terkena oleh berbagai macam malapetaka, kuat, serta awet muda. Makhluk hasul yang sering disebutnya kebanyakan makhluk yang suka menolong dengan katerogi baik. Adapun makhluk jahat yang disebut dalam ajian berkaitan dengan magis hitam seperti santet.

Contoh Puisi Mantra Ajian:

\section{Sima}

Sima méong sima mereka

sima méong pindah kana irung

sima sérab pindah kana mata

sérab ku kaserangan

Puisi mantra di termasuk pada kelompok puisi mantra ajian, terlihat dari kalimat sima sérab pindah kana mata, sérab ku kaserangan. Dari kalimat tesebut memiliki maksud dan tujuan supaya yang melafalkan mendapatkan kekuatan pada dirinya.

\section{Singlar}

Singlar mempunyai tujuan untuk mengusir hantu, kuntilanak, makhluk halus yang sering mengganggu manusia. Sisi lain singlar digunakan untuk mendapatkan keselamatan, juga keberkahan untuk tujuan yang baik-baik. Makhluk halus yang sering disebut dalam singlar yaitu makhluk-makhluk jahat yang akan disinglar seperti kuntilanak, hantu, hama, sukma musuh, sukma buaya serta setan.

Contoh Puisi Mantra Singlar:

\section{Panyinglar ka leuweung}

Aki koronjok kosong

Nini koronjok kosong

pang ngosongkeun jalan kula

ulah aya nu ngarogahala

Puisi mantra di kategorikan pada puisi mantra singlar, terlihat dari kalimat pang ngosongkeun jalan kula, ulah aya nu ngarogahala. Dari kalimat tersebut mempunyai tujuan untuk menyinglar suatu tempat dan yang melafalkan diberikan keselamatan.

\section{Rajah}

Rajah digunakan ketika mendatangi suatu tempat yang angker, membuka lahan untuk bertani, akan mendiami suatu tempat, bertujuan untuk dijauhkan dari siluman-siluman juga dedemit, penjagaan dari orang-orang yang berbuat jahat terhadap kita, dan memusnahkan impian buruk. Makhluk yang sering dilafalkannya adalah makhuk halus baik dan makhluk halus jahat.

Contoh Puisi Mantra Rajah:

\section{Pangrajah}

Bismillahirohmanirrohim

Rajah aing rajah pamunah 
dipunahkeun sia kapunah

ngabadi sia ka abdi

ong buta kasundulan

ong buta kasanolilan

bleg bumi bleg langit

bleg manusa nya aing nu nyaho

nu calik didasar

Sang Gelempeng putih nya aing

nu nyaho nu dasar jadi

Radén Maya Réla Réla Maya

aing nyaho nu calik di sah Nyai

Radén Una Djaya Una

pada patut pada runtut

ka cai jadi saleuwi

ka darat jadi salebak

oré-oré papakaré

siluman anu kawasa

manusa anu wisésa

Ya Allah Ya Rasullullah

Puisi mantra di atas termasuk kepada puisi mantra rajah, dapat terlihat dari kalimat rajah aing rajah pamunah, di punahkeun sia kapunah. Dari kalimat tersebut mempunyai maksud dan tujuan supaya yang membacakan terhindar dari bahaya, dan dijauhkan dari gangguan siluman jahat, dan dijauhkan dari orang yang berniat jahat.

\section{Jampé}

Jampé atau jampi mempunyai tujuan untuk menyembuhkan orang sakit dan kecelakaan seperti terjatuh, terkena kalajengking, dan penyakit lainnya.

Contoh Puisi Mantra Jampé:

\section{Jampé raheut}

Pegat sumsum tepung sumsum

pegat tulang tepung tulang

pegat daging tepung daging

pegat urat tepung urat

pegat lamad tepung lamad

pegat kulit tepung kulit

pegat bulu tepung bulu

pet rapet nu rapet Sangkama putih
Pada puisi mantra di atas termasuk kepada puisi mantra jampé, dapat terlihat dari kalimat pegat bulu tepung bulu, pet rapet nu rapet Sangkama putih. Dari kalimat tersebut mempunyai tujuan untuk menyembuhkan orang sakit.

\section{Struktur Puisi Mantra di Kecamatan Situraja Kabupaten Sumedang}

Iskandarwassid (2016, hlm. 227)

menyebutkan bahwa struktur dalam sastra adalah suatu komponen-komponen karangan yang menghasilkan berupa wujud karya sastra yang mempunyai makna. Dalam artian strukturalisme mempunyai makna yang merupakan kesatuan dari struktur yang mendukungnya. Sehingga dapat disimpulkan bahwa, analisis struktural merupakan kajian yang mengacu kepada penelitian yang mengharuskan kepada peneliti untuk mendalami isi dari suatu karya, untuk memudahkan dalam memahami struktur pembangunnya. Sesuai dengan konsep Rusyana, menyebutkan bahwa, puisi mantra mempunyai unsur purwakanti, sajak wirahma merdika, dan bangbalikan.

Unsur-unsur puisi mantra yang dianalisis dalam penelitian ini yaitu: 1) teks mantra, judul mantra, nomer mantra; dan 2) analisis struktur puisi mantra, meliput: wangun jeung wirahma, purwakanti (pangluyu, maduswara, cakraswara, laraspurwa, larasmadya, larawekas, mindoan kawit, jeung margaluyu), bangbalikan (rantay jeung runtuy), serta pencitraan (penglihatan, pendengaran, dan perasaan) yang terdapat pada puisi mantra. Wangun jeung wirahma mantra dalam penelitian ini sejalan dengan konsep Rusyana. Dalam wangun jeung wirahma tidak berpatokan sama. Terlihat dari hasil analisis dalam penelitian ini terdapat wangun jeung wirahma paling sedikit ada 3 baris dan yang terbanyak 20 baris. Tetapi yang sering ditemukan kebanyakan 8 baris dengan pola 4-4, 3-5 dan 5-3. 
Purwakanti merupakan nada dasar suara antara dua engang atau lebih dalam kata yang berbeda. Dalam penelitian ini purwakanti yang sering muncul adalah purwakanti mindoan kawit, larasmadya, laraspurwa, dan laraswekas. Dari banyaknya purwakanti yang ada, berpengaruh pada sugesti yang dipercaya masyarakat bahwa mantra dianggap mempunyai kekuatan. Hal ini terlihat dalam salah satu purwakanti mindoan kawit dalam mantra ngembat Nyi Sri dengan kode (02.01.007) yaitu:

Anta rasa anta sari

anta rupa anta bukti

Malaikat sang tada sakti

malaikat sangka masalah

Dari contoh di atas terdapat purwakanti mindoan kawit dari kata anta dan malaikat.

Contoh purwakanti larasmadya:

Asihan aing batu menur

di tumpangan batu welas

Diambil dari mantra Asihan I (03. 01.011). terdapat kata batu yang termasuk ke dalam purwakanti larasmadya.

Contoh purwakanti laraspurwa:

\section{Pada patut pada runtut}

Dari sempalan di atas yang diamil dari mantra Pangrajah (07.16.051) yang termasuk kedalam laraspurwa yaitu kata depan $p a$ yang disebut di setiap awak kata. Contoh purwakanti laraswekas:

\section{Diteuteup ti hareup sieup}

Dari sempalan di atas terdapat akhiran dengan vokal yang sama yaitu eup. Contoh tersebut diambil dari mantra Asihan Si Ratu Gambuh (05.03.026).

Bangbalikan dina puisi mantra di kecamatan Situraja, ada dua bangbalikan yang sering muncul dalam mantra yaitu bangbalikan rantay rakitan a b/ a c jeung bangbalikan runtuy puhu.

Contoh bangbalikan rantay rakitan a $b / a$ $c$ :

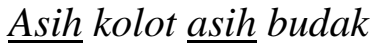

Terlihat dari sempalan di atas yaitu kata pertama diulang kembali di kata ketiga.

Contoh bangbalikan runtuy puhu:

Aki bayu hawa

Aki buyut ka kawah

Aki senték waja

Terlihat dari sempalan di atas menunjukan bahwa bangbalikan runtuy puhu, sebab kata yang diulang kembali terdapat di setiap awal baris.

Citraan yang sering muncul dalam penelitian mantra ini yaitu citraan panempo (visual) jeung citraan pangrasa (taktil). Dalam citraan panempo yaitu terlihat dalam:

\section{ditilik ti gigir lengik,}

diteuteup ti hareup sieup,

ti hareup Rangga Arjuna,

ti tukang Rangga Déwata.

Citraan panempo terlihat dari kata ditilik, diteuteup yang berkaitan dengan penglihatan.

Adapun citraan pangrasa dapat terlihat dalam beberapa larik seperti:

mangka welas mangka asih, asih ka diri awaking, sing nyerep

ka ati sununing bari,

ngabdi sia ka abdi,

pada patut pada nurut.

Dari sempalan tersebut terlihat bahwa citraan pangrasa terdapat pada kata welas asih yang berkaitan dengan perasaan. Umumnya dari setiap puisi mantra yang terkumpul di Kecamatan Situraja, Kabupaten Sumedang kebanyakan dari puisi mantra digunakeun untuk hal-hal yang baik, seperti dalam penyembuhan orang yang sakit, dan kebanyakan ajian yang digunakeun untuk keraharjaan.

\section{SIMPULAN}

Puisi mantra termasuk pada genre puisi buhun, adapun puisi buhun berupa hasil transkripsi dari bahasa lisan yang mempunyai kekuatan magis. Di 
Kecamatan Situraja, Kabupatén Sumedang dari hasil data yang telah terkumpul ada beberapa mantra yang masih dimiliki oleh beberapa orang pintar atau dukun. Desa di Kecamatan Situraja, Kabupaten Sumedang ada 15 desa. Dari 15 desa, yang dijadikan sampel dalam penelitian ini ada 4 Desa yaitu: Desa Situraja, Desa Situraja Utara, Desa Mekarmulya, dan Desa Malaka. Dibawah ini merupakan puisi mantra yang terkumpul dan terinventarisir di kecamatan Situraja Kabupaten Sumedang terdiri dari 105 mantra yang dibagi jadi enam bagian yang meliputi: 22 asihan, 22 jangjawokan, 38 ajian, 6 singlar, 3 rajah, 14 jampé. Pengklasifikasian ini berdasar pada teori Rusyana dan konsep kriteria klasifikasi mantra Isnendes, yang mengelompokan mantra berdasar pada fungsi dan tujuan mantra. Puisi mantra yang banyak ditemukan berupa ajian. Wangun dan wirahma yang sering ditemukan dibangun oleh 8 baris dengan pola 4-4, 3-5, dan 5-3. Dalam purwakanti yang sering ditemukan adalah purwakanti mindoan kawit, larasmadya, laraspurwa, dan laraswekas. Sedangkan purwakanti mindoan kawit jarang ditemukan dalam penelitian ini. Bangbalikan yang sering muncul adalah bangbalikan rakitan a b/ a c dan bangbalikan runtuy puhu. Dalam citraan yang sering ditemukan adalah citraan visual dan citraan taktil.

\section{DAFTAR PUSTAKA}

Cahyadi, A.D. (2014). Kajian Struktural, Stilistika, dan Etnopedagogi dalam Kumpulan Puisi (Sajak) Periode Tahun 2000-an. LOKABASA: Jurnal Kajian Bahasa, Sastra, dan Budaya Daerah serta Pengajaran, 5 (1) 2014, 1-110.

Iskandarwassid. (2016). Kamus Istilah Sastra. Bandung: Geger Sunten.

Isnendes, R. (2010). Teori Sastra. Bandung: CV. Wahana Karya Grafika.
Hutomo, S. S. (1991). Mutiara yang Terlupakan: Pengantar Studi Sastra Lisan. Surabaya: HISKI Jawa Timur. Jaya, S., R. Sahrul., \& Ermanto. (2013). Peningkatan Keterampilan Menulis Puisi Melalui Media Gambar Siswa Kelas X.1 SMA Negeri 2 Kota Sungai Penuh. Jurnal Bahasa, Sastra dan Pembelajaran, 1, 88-95. Diaksés ti: ejournal.unp.ac.id.

Koswara, D. (2013). Racikan Sastra. Bandung: Jurusan Pendidikan Bahasa Daerah Universitas Pendidikan Indonesia.

Pudentia. (2008). Metodologi Kajian Sastra Lisan. Jakarta: Asosiasi Tradisi Lisan.

Retnaningsih, W. (2012). Memahami Bahasa Mantra Dalam Jagat Budaya Jawa. Journal of Rural and Development, 1, 75-86. Diaksés ti: jurnal.uns.ac.id.

Rusyana, Y. (1970). Bagbagan Puisi Mantra Sunda. Bandung: Projek Penelitian Pantun dina Folklore Sunda.

Sugiyono. (2016). Metode Penelitian Kuantitatif, Kualitatif, dan R\&D. Bandung: Alfabeta.Suyatna, A. (2002). Pengantar Metodologi Pendidikan Dan Pengajaran Bahasa. Bandung: Departemen Pendidikan Nasional Universitas Pendidikan Indonesia.

Sukardi. (2013). Metodologi Penelitian Pendidikan: "Kompetensi dan Praktiknya.". Jakarta: PT Bumi Aksara

Suyatna, A. (2002). Pengantar Metodologi Pendidikan dan Pengajaran Pendidikan Indonesia. Bandung: Departemen Pendidikan Nasional Universitas Pendidikan Indonesia Fakultas Pendidikan Bahasa dan Seni Jurusan Pendidikan Bahasa Indonesia dan Daerah.

Wellek, W. (2014). Teori Kesusastraan. Bandung: PT. Gramedia Pustaka Utama. 


\section{UCAPAN TERIMA KASIH}

Segala puji dan syukur dihaturkan pada Allah swt, sebab rahmat dan hidayah-Nya artikel ini bisa selesai. Terima kasih pada semua pihak yang telah membantu dalam mengumpulkan serta menganalisis data dalam penyusunan artikel ini. Semoga dengan adanya artikel ini bisa bermanfaat untuk perkembangan keilmuan sastra Sunda. Dalam artikel ini pasti ada beberapa kekurangan, oleh karena itu penekiti menerima kritik dan saran yang membangun agar artikel ini kedepannya bisa lebih sempurna. 